\title{
A QUALIDADE NO ATENDIMENTO: O futuro das agências de turismo
}

\section{QUALITY IN SERVICES: The future of travel agencies}

\author{
Elton José da Silveira (SILVEIRA, E. J. da)*
}

\begin{abstract}
RESUMO - Neste artigo se aborda o panorama atual do mercado das agências de turismo no Brasil, traçando uma análise entre empresas virtuais de vendas de turismo e as agências de turismo físicas, quais suas perspectivas e preocupações necessárias, tendo em vista o cliente como grande fomentador desse mercado. Sendo assim, o artigo foca no atendimento ao cliente nas agências de turismo, suas particularidades e diferenciais. Quais critérios devem ser atendidos e verificados pelas agências para que possam atender às novas necessidades de um mercado cada vez mais exigente e competitivo? O cliente passa a ter a opção de escolha entre comprar diretamente os serviços de turismo ou fazê-lo através de uma agência de viagens, quais os perfis e critérios que definem a compra das pessoas? É o que no artigo se procura analisar.
\end{abstract}

Palavras-chave: Atendimento; Venda; Pós-Venda; Agenciamento; Relação AgenteCliente; Tecnologias.

ABSTRACT - This article discusses the current panorama of the Tourism Agencies market in Brazil, tracing an analysis between virtual enterprises the sells tourism and the physical Tourism Agencies. What are their perspectives and concerns, focusing in the client which is the biggest developer of this market. The article focuses on customer service quality provided by travel agencies, its features and differentials. What criteria should be applied and checked by travel agencies professionals to attend the new needs of a market that is more and more demanding and competitive? Does the customer have the option to choose between buying directly his tourism services or do it through a Travel Agency? What are profiles or criteria that define the purchase? That is what this article seeks to analyze.

Key words: Service; Sales; After-Sales; Agency; Agent-Customer Relationship; Technology.

\footnotetext{
* Formação: Graduação em Comércio Exterior pela FATEC INTERNACIONAL/Curitiba/PR; Graduação em Belas Artes pela EMBAP/PR. Mestrado em Engenharia de Produção pela Universidade Federal de Santa Catarina (UFSC). Atividade profissional: Diretor da agência de turismo - B4 Travel. Endereço físico para correspondência: Av. Paraná, 1030, sala 8. CEP: 80035-130 - Curitiba/PR - Brasil. E-mail: elton@b4travel.com.br
} 


\section{INTRODUÇÃO}

É bastante frequente ler ou escutar de profissionais da área de agenciamento, frases ou perguntas, como: Estamos perdendo mercado; A internet está fechando as agências de viagens; $\mathrm{O}$ cliente compra tudo por conta própria; Como sobreviver a fornecedores que são nossos concorrentes?

O que se pode concluir a partir dessas indagações? Sim, o mercado está passando por grandes mudanças, numa velocidade que muitos ainda não se deram conta e outros não conseguem alcançar, o que faz com que os empresários do mercado de agenciamento no Brasil, e também no mundo se questionem e principalmente, tenham que se reinventar. Reinvenção é a palavra de ordem, como oferecer ao mercado aquilo que ele busca? Por certo a melhor maneira de iniciar tal investigação é compreendendo o que é realmente o agenciamento, quais suas perspectivas, suas ferramentas, seus limites, concorrência e quem ainda busca este serviço? Os que não o buscam em agências de turismo, o fazem de qual maneira? E por quê? Eis algumas questões que neste artigo se procurará analisar.

\section{AGENCIAR: A ARTE DE SE COMUNICAR}

Agenciar, segundo o Dicionário do Aurélio (2015) é "Trabalhar para adquirir ou obter. Tratar negócio alheio na qualidade de agente. Conseguir obter”. Segundo o dicionário Michaelis (2015), significa: "Negociar, procurar, solicitar. Fazer por encontrar“، A pergunta que vem após essas definições de agenciar é: Trabalhar para adquirir ou obter o que exatamente? Para quem especificamente? Este mergulho inicial no conceito básico do verbo abre um leque de possibilidades e rumos a serem pensados e buscados pelo agente de viagem, antes de simplesmente seguir um template de rotina e ir buscar aquilo que se quer vender, ou o que de rotina o mercado consome, deve-se pensar que este modelo nem sempre é o que ao cliente irá interessar.

Muitas vezes envia-se uma cotação a um cliente e obtém-se como resposta o famoso "vou pensar e te respondo", é fácil colocar a culpa no mercado competitivo, ou na incapacidade do cliente pagar pela viagem, afinal são duas variáveis a serem 
consideradas, mas são apenas duas de muitas outras que são normalmente subestimadas. É nessa subestimação que consiste a verdadeira lacuna do agente perante o atendimento ao seu cliente.

A comparação ao atendimento com outras áreas pode ajudar a esclarecer alguns problemas e reações entre cliente e profissional. Utilize-se como exemplo o atendimento médico, se o médico negligenciar alguma sequência anamnéstica, certamente se perderá alguma informação importante para o resultado final da consulta, que é oferecer ao cliente um diagnóstico completo, de acordo com suas necessidades e expectativas.

Quantas vezes um paciente deixa um consultório com a sensação de insatisfação em relação ao médico? Onde está o problema? Mas, o consultório é lindo, o médico super bem formado, os exames foram solicitados, quase tudo correra bem, porém, o paciente não sentiu segurança no profissional e logo marca uma segunda ou terceira consulta com outro profissional, até achar aquele que estabeleça, o que na medicina chama-se relação médico-paciente.

Aí está a frase que é a essência deste artigo - estabelecer relação. Voltando à definição de agenciar, por Dicionário do Aurélio (2015), que discorre ser "Tratar negócio alheio na qualidade de agente", negócio alheio? Termo este que se torna uma grande chave do sucesso desta relação entre agente e cliente. Se o negócio é alheio, não valeria investigar com bastante profundidade a necessidade do outro? Mostrando interesse, não apenas tratando o assunto como uma rápida investigação do destino pretendido? Ou uma breve compreensão do perfil do cliente? Não raro aparecem os famosos templates, neste caso, tentando brevemente enquadrar em que molde o cliente se encaixa, no perfil cultural? Ou no de sol e praia?

A alegação da maioria dos agentes de viagens é de que não existe tempo para se dedicar a muita conversa. Outra questão bastante importante é a existência de dois grandes perfis de negócios que têm de se ter claros ao planejamento estratégico de uma agência de viagens e, por conseguinte, ao agente de viagem. Minha escolha de negócio é voltado ao turismo de massa e generalista, ou meu mercado é direcionado a um segmento qualquer?

Se a opção de negócio é para atender o turismo de massa, voltado a pacotes prontos ou pré-formados, onde o cliente tem pouca, ou às vezes nenhuma opção de alteração, resta então apenas escolher o tempo da viagem e o destino em questão. Neste 
perfil os templates são os modelos mais adequados mesmo, porém, isso não exime a empresa, seja ela com estrutura física ao cliente ou virtual, de oferecer um amplo canal de relacionamento, onde a qualquer momento das três fases do negócio, pré-venda, venda e pós-venda, o cliente possa esclarecer dúvidas de qualquer ordem, seja ela sobre o custo, destinos, equipamentos ou mesmo sobre possibilidades de extensões, cancelamentos e reembolsos.

Investigou-se os canais disponíveis de atendimento ao cliente nos quatro principais canais de venda virtual de pacotes e serviços no Brasil, na internet, e por questão de privacidade, as quatro empresas foram denominadas de $\mathrm{X}, \mathrm{Y}, \mathrm{Z}$ e W, respectivamente. A página inicial destas empresas, cujos prints de seus sites estão em ANEXOS neste artigo, sem suas logos ou nomes verdadeiros, foram analisadas no que se refere aos canais de atendimento ao cliente, quais eram estes canais e se realmente funcionavam, simulou-se uma pesquisa de compra de um produto, sem que nenhuma tenha sido efetivamente finalizada e adquirida, de um destino saindo de Curitiba (Paraná, Brasil), até Natal (Rio Grande do Norte, Brasil), período fictício referente a 12 a 19 de maio de 2015.

A empresa $X$, estava oferecendo em sua página inicial um canal de atendimento ao cliente, apenas para produtos adquiridos, caso o cliente tivesse alguma dúvida sobre o produto, sem contratá-lo antes, ele não tinha esse canal de comunicação, pois, tentando acessar onde constava: "Atendimento ao cliente" abria-se um questionário com diversos campos, mas alguns sendo obrigatórios de serem preenchidos, num deles se pedia o número da reserva do produto, e no outro se pedia um email, que quando se tentava preencher, não aceitava símbolos como “@” ou pontos e vírgulas.

O telefone teria que ser uma ligação interurbana, que quando acionado o cliente que arcaria com o custo, sem ter, muitas vezes, a informação desejada, pois os atendentes não possuíam, na maioria das vezes, acesso ou formação para prestar muito mais informação daquela disponibilizada no descritivo básico do produto.

A empresa Y estava oferecendo um canal de ajuda on line e um denominado "ajuda on line" na própria página do site, na imagem 2 de ANEXOS pode-se observar uma seta maior indicando que o canal de ajuda on line apresentava-se indisponível para ser utilizado, o que indicou a precariedade e a pouca opção de atendimento ao cliente, da mesma forma o cliente teria de ligar a um custo interurbano e obter informações 
bastante básicas com o atendente do telemarketing, o qual não tem, normalmente, um treinamento adequado, como é praxe na maioria dos canais de telemarketing, foi feito o teste de pedir informações sobre os serviços buscados e a sensação de atendimento insuficiente se mostrou real.

No outro canal intitulado "dúvidas" se abriu um questionário, que se copiou para a IMAGEM 2, oferecendo a opção de enviar via email sua dúvida e ter de esperar o tempo que eles definissem para resposta, o que nem sempre é viável ou retornasse com a resposta desejada no tempo que o cliente necessitava, tendo de se repetir o procedimento o número de vezes que fossem necessárias.

A empresa Z, representada em ANEXOS pela IMAGEM 3, não estava oferecendo visivelmente em sua página inicial, um contato efetivo entre atendente e cliente, a menos que a pessoa se cadastrasse previamente, o que estaria indo contra às regras do direito do consumidor, que não é obrigado a divulgar dados pessoais em troca de informações comerciais involuntariamente.

A empresa W representada em ANEXOS, pelas imagens 4 e 5, estava oferecendo um canal para os que possuíam reserva apenas, e não conseguiam responder, nem mesmo por telefone, em seu serviço 0800, detalhes do destino ou do serviço, sugeriam que o cliente entrasse em contato direto com o hotel para maiores informações, e caso o cliente tivesse algum pedido especial, não conseguiriam atender, como por exemplo, reserva de quarto especial para deficiente físicos, ou quarto conjugado para famílias, este serviço foi informado que deveria ser solicitado diretamente com o hotel.

No serviço de apoio ao cliente do site, abria uma página direcionada aos que já tinham reserva, até existia um questionário para ser enviado com espaço para perguntas, mas as respostas eram pré-concebidas, mais insuficientes ainda que no serviço 0800 disponível.

Ou seja, no site se conseguia atender parcialmente ao cliente, estabelecendo uma relação insuficiente com o mesmo, a venda, neste caso, fora focada basicamente em preços, tendo o cliente de se inteirar por conta própria sobre o produto, muitos dos clientes teriam de se valer de redes sociais e sites qualificadores disponíveis para isto.

Objetivou-se com estes quatro exemplos mostrar o perfil das empresas e a relação entre clientela e os serviços virtuais prestados pelas empresas, este público 
buscado consome preferencialmente por preços, independente da categoria e do custo do serviço buscado, existe na visão dessa clientela, uma clara compreensão de que a agência de turismo é uma intermediária e, sendo assim, encarece o produto quando acionada.

Considera-se que falta um trabalho sério das entidades de classe dos agentes de viagens que focam em capacitação básica de agentes e em eventos ligando agentes de viagens a fornecedores de serviços, esquecendo-se de que um dos principais atores para o sucesso do trade é o cliente. Há de se pensar em informar também àquele que compra, e não apenas aos business trades. Há muita incompreensão acerca do papel do agente de viagem neste mercado.

Então quem de fato consome os serviços de agências de viagens? Considera-se ficar claro que o consumo das agências está basicamente em três setores:

1) Parcerias com eventos,

2) Turismo de lazer,

3) Turismo corporativo.

Os demais segmentos permeiam estes três grupos, o que muda é a finalidade da viagem, ecoturismo, por exemplo, está fortemente ligado ao prazer, ao lazer, ao desfrute da natureza de forma sustentável, mas ficando claro que tem suas peculiaridades e não dispensam profissionais capacitados e com ampla formação específica para atender a este mercado, amplo e da mesma forma sensível ao manejo inapropriado.

Não se quer com este artigo desqualificar os segmentos do turismo, muito pelo contrário, pois, provoca-se um olhar para quais cuidados os agentes deveriam ter em relação ao conhecimento e atendimento de seus clientes, reconhecendo quem de fato são os clientes e quais necessidades os mesmos têm, bem como, de que forma estabelecer a grande relação cliente-agente.

Atrair a atenção do cliente é o grande trabalho do marketing, que foca na venda, há de se pensar o turismo sob o ponto de vista da demanda, quem é o meu cliente? $\mathrm{O}$ que ele quer? O que ele pode? $\mathrm{O}$ que pode ser agregado ao mesmo, desde o primeiro contato, pois, esquece-se que quando um alguém entra numa agência, ele busca uma realização, um ganho, mesmo que não compre nada, tem de sair da agência com algum valor agregado a mais daquele inicial. 
Uma informação atrativa, uma perspectiva diferenciada, um destino bem sugerido e motivado, enfim, um universo que o estimule a consumir e, consumir neste caso não é necessariamente comprar, as melhores vendas vêm de indicações, todos que trabalham no trade sabem que quando se impressiona alguém, ganha-se um admirador, uma pessoa que quando escutar a palavra viagem, lembrará de quem o impressionou sobre o assunto no momento de buscar ou indicar algo. $\mathrm{O}$ agente de viagem é um grande formador de plateia, um encantador de mentes, capaz de plantar uma semente de curiosidade, pronta para germinar no momento e lugar certo.

Outra questão a ser verificada pelos agentes de viagens é onde se inicia a pósvenda? A maioria acha que a pós-venda é feita no retorno do cliente, onde o agente faz o trabalho diplomático de checar se tudo correu de acordo com a necessidade do viajante, coletar informações e dicas para aprimorar sua rotina de trabalho, seus fornecedores, destinos, serviços vendidos.

Isto tudo é fato, tem mesmo que ser realizado e consumado, porém, existe um grande limbo entre o momento de fechamento do negócio, onde o cliente tomou a decisão e contratou o serviço, e a data do embarque, que em lazer quase nunca é imediato, diferente do corporativo, não raro pessoas compram com uma boa antecedência, pois, sabem que os custos tendem a ser menores e a disponibilidade é mais bem atendida. Pode haver um espaço de muitos dias e até meses entre a compra e o embarque, neste espaço de tempo é comum o cliente ficar desassistido, afinal, tudo está confirmado, reservado e pago, salvo alguma alteração ou cancelamento involuntário de serviços, o cliente fica solitariamente esperando por sua viagem.

Pois bem, a pós-venda também compreende esse período, e é frustrante quando se é ignorado como consumidor, sendo valorizado até o momento do pagamento do serviço apenas. A motivação e o contato devem ser contínuos, é como se o agente de viagens acolhesse seu cliente e o motivasse até o momento do embarque, como? Com informações periódicas sobre o destino, com avisos de atrações que ocorrem no local e período da viagem do mesmo, muitos dos quais gratuitos, para não configurar apenas o interesse financeiro do repasse de comissão.

Artigos relacionados com a viagem devem ser enviados por email, claro que dependendo do perfil de cada cliente, para isso a importância de um amplo conhecimento da clientela por parte da agência e do agente. 
Num planejamento estratégico de uma agência de turismo, não é raro se deparar com planos bem estruturados, detalhando qual mercado interessa à agência e como se pretende atingir tais metas. Mas o principal pouco se desenvolve, ou se planeja, e quando se descreve, na prática, pouco se cumpre.

Não se tem conhecimento aprofundado que perfil individualizado o(s) $\operatorname{seu}(\mathrm{s})$ cliente(s) possui(em)? Existe algum tipo de CRM (Customer relationship management) que a agência utilize como rotina para monitorar e atender diversos perfis de clientes? Evitando incomodar sua clientela com envios pífios de produtos inadequados. Um cliente de perfil cultural elevado e de bom poder aquisitivo, habitué de viagens, não quer ficar recebendo pacotes de uma semana em Porto Seguro (BA) todos os meses. Sente-se tratado como mais um dentro de uma lista de spam aleatório. Conhecer quem de fato sua agência atende e como pensa seu cliente é tão importante quanto conhecer sobre destinos e saber operacionalizá-los. Estas são questões com as quais poucas agências de fato se preocupam.

Quando se aborda um segmento exigente, que trabalha bastante, com pouco tempo para viajar e que, por já ter experimentado contratar viagens por uma boa agência de turismo, ou por não querer se envolver com riscos, principalmente em se tratando de viagem de férias, muitas vezes com família viajando junto, estas pessoas não querem espaço para grandes riscos. Buscam profissionais em quem confiem, e que de preferência antecipem a solução do possível problema, reconfirmando com diversos atores os serviços reservados, já antes da viagem, imprimindo confirmações e anexando tais emails nos documentos e vouchers de viagem do cliente, e se após esse cuidado, algo sair errado, afinal o agenciamento depende de terceiros, mas se algo falhar, o cliente sabe que a qualquer momento tem alguém experiente e ágil para ajudá-los em seus problemas e contratempos.

A este cliente a internet pouco atrai, não convence, e é neste grupo que as agências de viagens que pretendem permanecer no mercado devem investir. Investimento não só de aporte financeiro na compra e uso de equipamentos e tecnologias que assistam seus clientes, mas também em tempo, este dedicado principalmente para dois atores:

1) $\mathrm{O}$ cliente, que deverá merecer bem mais que a hora dedicada à venda $\mathrm{e}$ questionamentos básicos, mas sim o tempo necessário para que se possa estabelecer o 
que identificou-se, neste artigo, como sendo a relação cliente-agente. Fundamental para a tão almejada fidelização da agência por parte do cliente, pois, engana-se quem pensa que a agência fideliza o cliente, mas sim o cliente fideliza-se com a agência, como um ator voluntário e ativo, e não como alguém passivo que apenas absorve o encantamento, sem critérios próprios ou poder de escolha.

2) $\mathrm{O}$ agente de viagens em si, o treinamento e conscientização da equipe deve estar afinada e constantemente adequado à cultura e prática da agência. É de fundamental importância que o agente de viagens não atropele esta relação e enxergue nela a única e melhor forma de manter e angariar mais clientes, o que define ou não a permanência da sua agência neste mercado, afinal não são apenas os fornecedores e produtos que se atualizam e se aprimoram, o cliente também passa pelo mesmo processo, sobrevivem aqueles que se atentarem e agirem neste sentido.

\section{CONCLUSÃO}

Num mundo globalizado, onde as tecnologias avançam numa velocidade além da capacidade de absorção pelas pessoas, deve-se estar atento às mudanças e necessidades, que também se alteram. As distâncias foram minimizadas, os serviços passam por uma sensível redução de preços, por conta de métodos e técnicas de gestão que otimizam recursos, barateando o produto a ser oferecido ao cliente.

Além de estimular novos mercados, novas oportunidades e novas abordagens, que se não forem identificadas e absorvidas, tornam-se fatais ao sucesso de empreendimentos turísticos, mesmo os agentes das empresas de tradicional vigor de mercado, são obrigados a rever suas estratégias e se adaptarem às novas tendências. Caso contrário, não conseguem sobreviver a este novo consumidor que tem acesso à informação e que sem sair de casa pode, através de ferramentas disponíveis a todos, contratar sua viagem, e muitas vezes negociar diretamente com fornecedores, conseguindo preços e benefícios importantes. Podem se unir em compras coletivas e se valer de negociações que antes eram acessíveis apenas a redes, empresas sólidas e grandes grupos. 
Para que uma agência sobreviva há de se investir naquele que é o principal ator desse mercado, o cliente, saber abordá-lo, conhecê-lo e estabelecer com ele uma relação de parceria e confiança. A este perfil de mercado haverá sempre espaço para os que dele conhecem e nele se aprimoram. A fidelização deve ser vista como um polo mútuo de influências e consequências, tanto o cliente como o agente precisam se empenhar, afinal a todos interessam um resultado de sucesso e uma boa perspectiva de futuro. Mas conhecer fisicamente os destinos que se vende, torna-se um grande diferencial para quem deseja fixar-se num mercado, onde a confiança e o conhecimento são importantes ferramentas comerciais.

\section{REFERÊNCIAS}

MICHAELIS. Agenciar. Disponível em:

$<$ http://michaelis.uol.com.br/moderno/portugues/index.php?lingua=portuguesportugues\&palavra=agenciar $>$. Acesso em: 13/04/2015.

DICIONÁRIO DO AURÉLIO. Significado de agenciar. Disponível em: <http://www.dicionariodoaurelio.com/agenciar>. Aceso em13/04/15. 


\section{ANEXOS}

\section{IMAGEM 1}

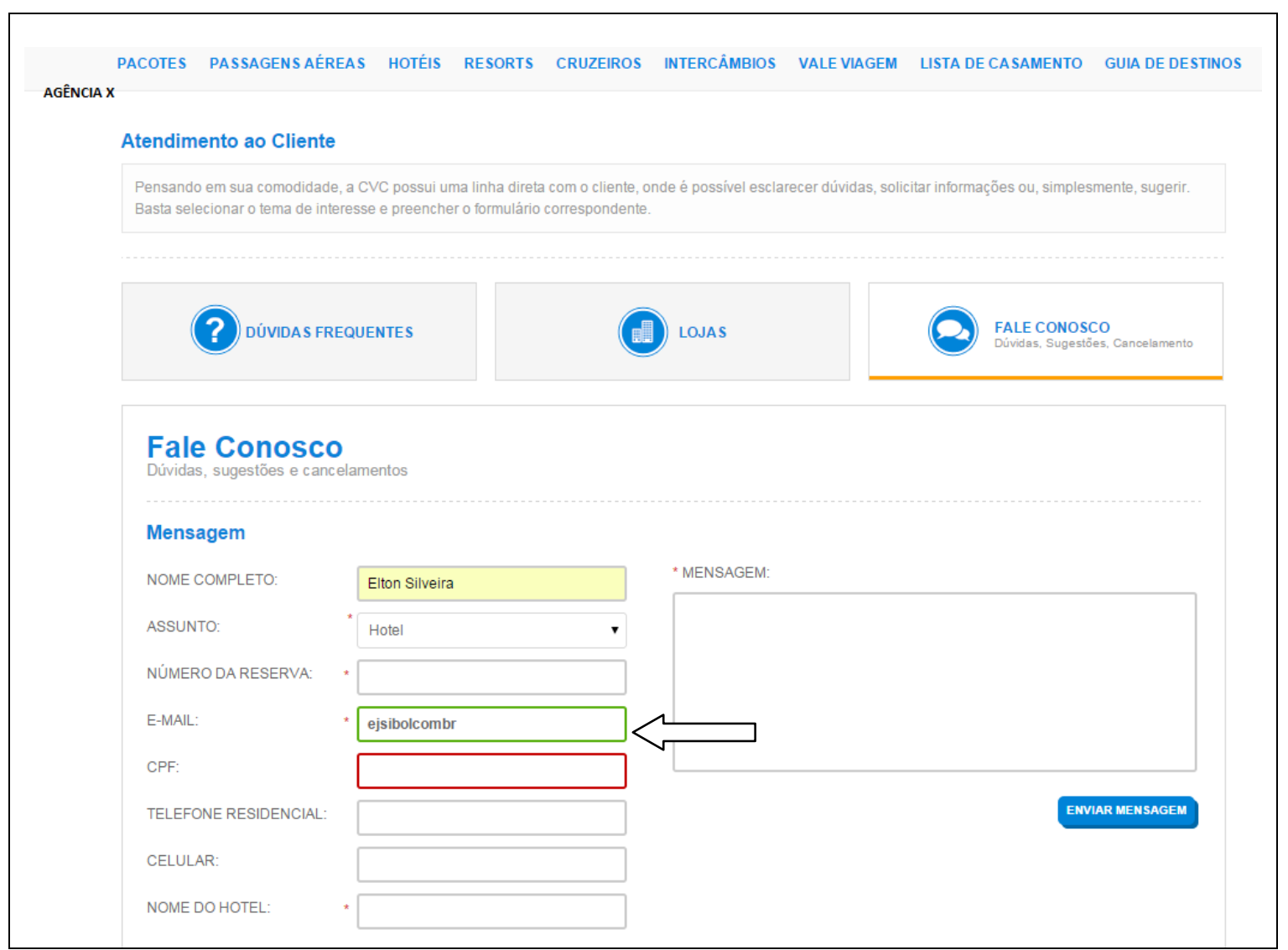




\section{IMAGEM 2}

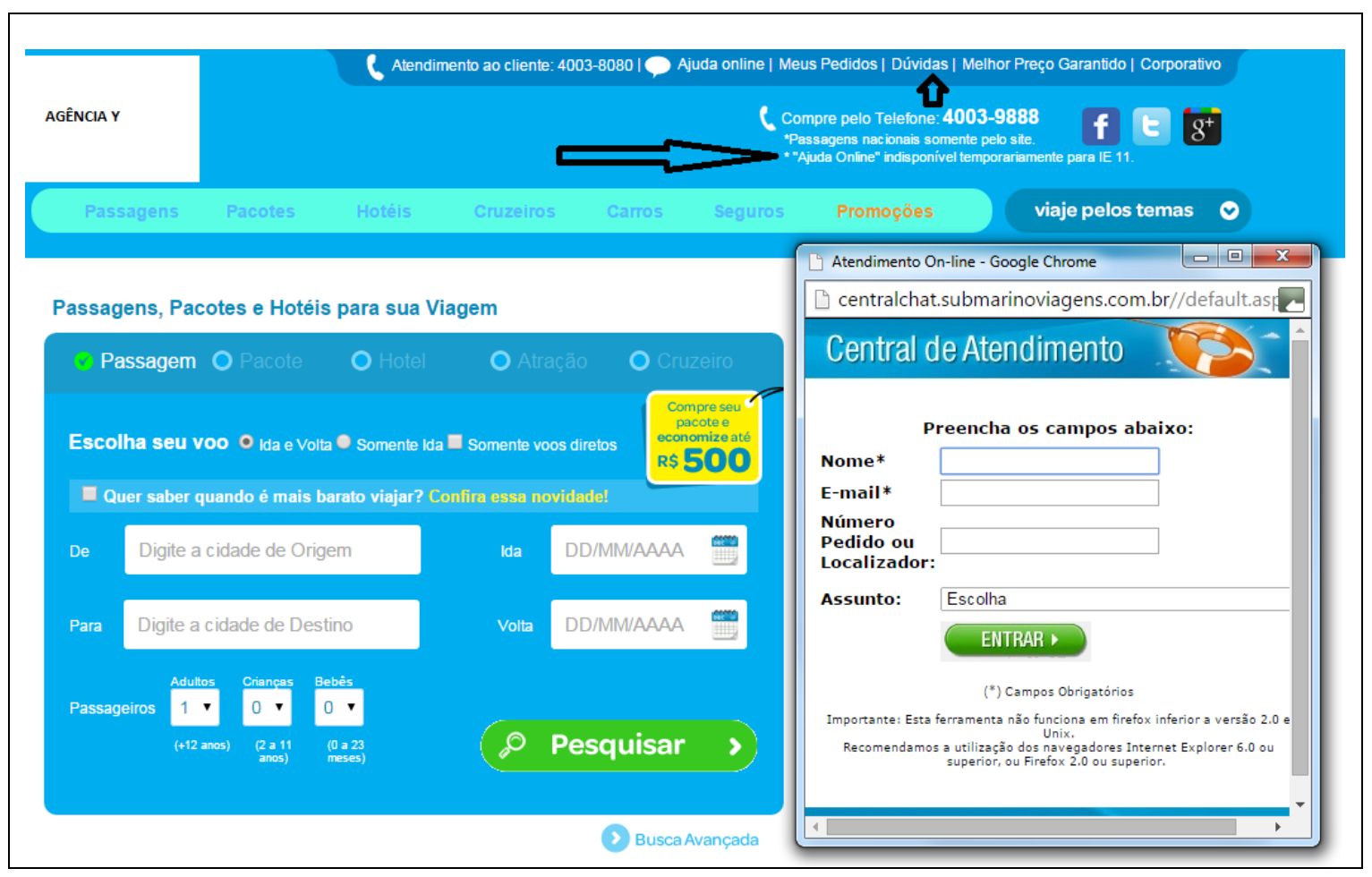




\section{IMAGEM 3}

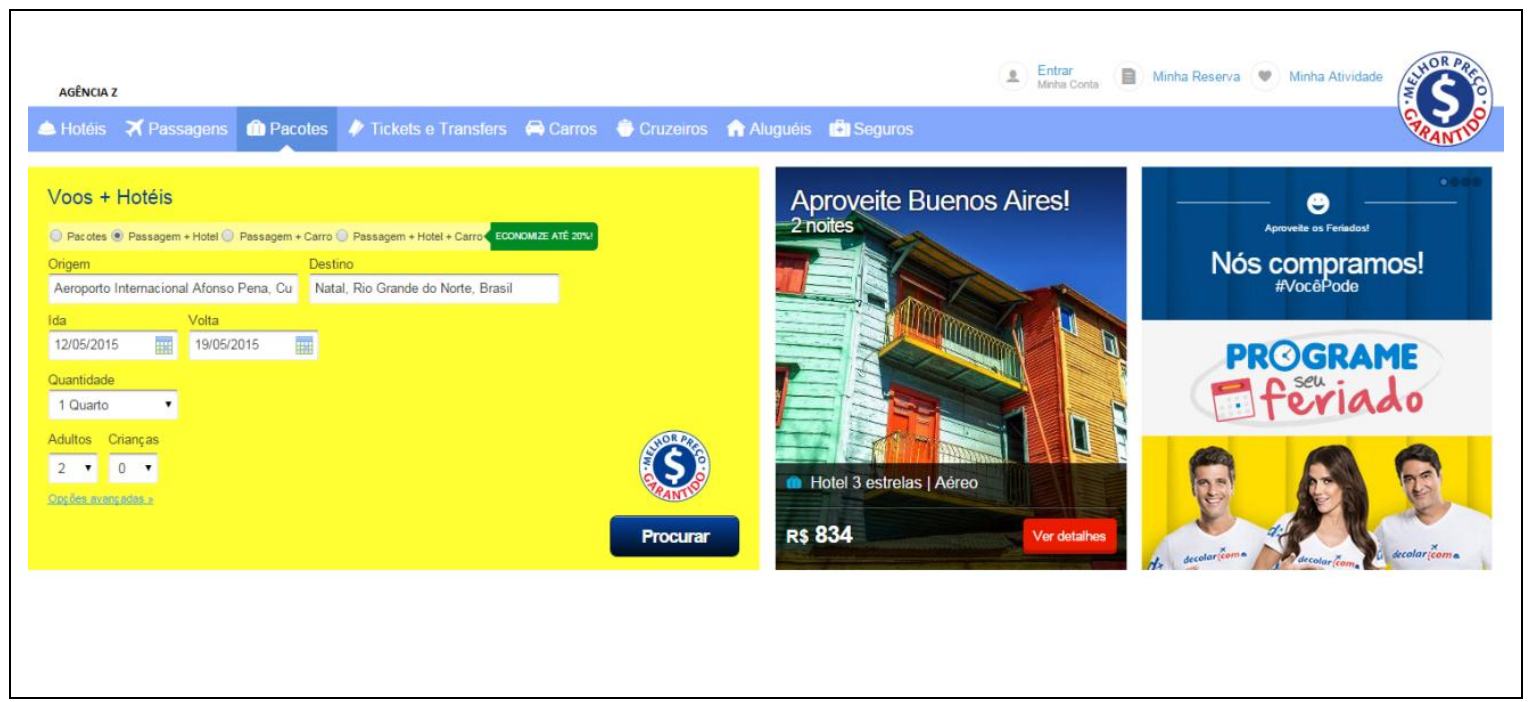




\section{IMAGEM 4}

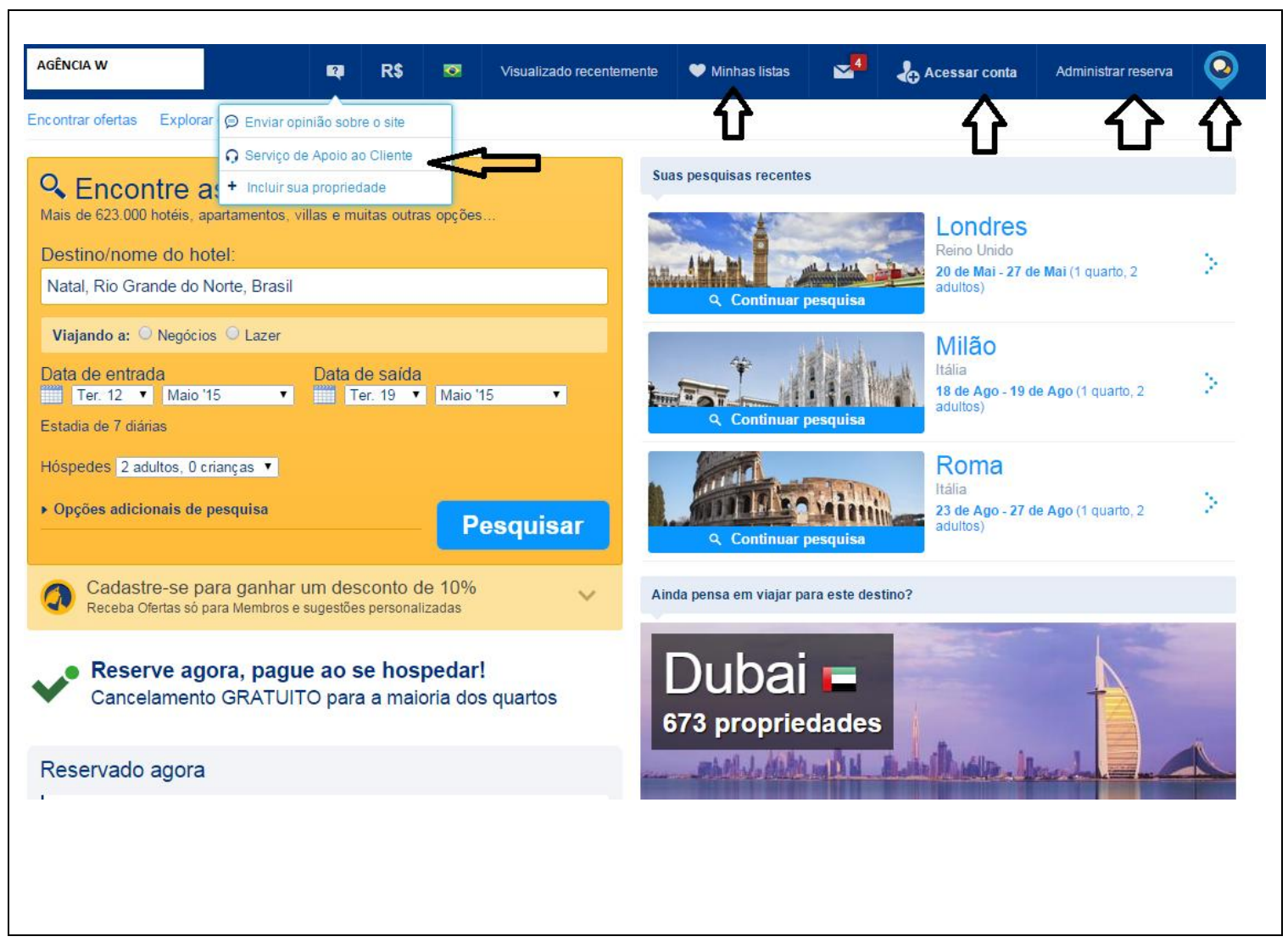




\section{IMAGEM 5}

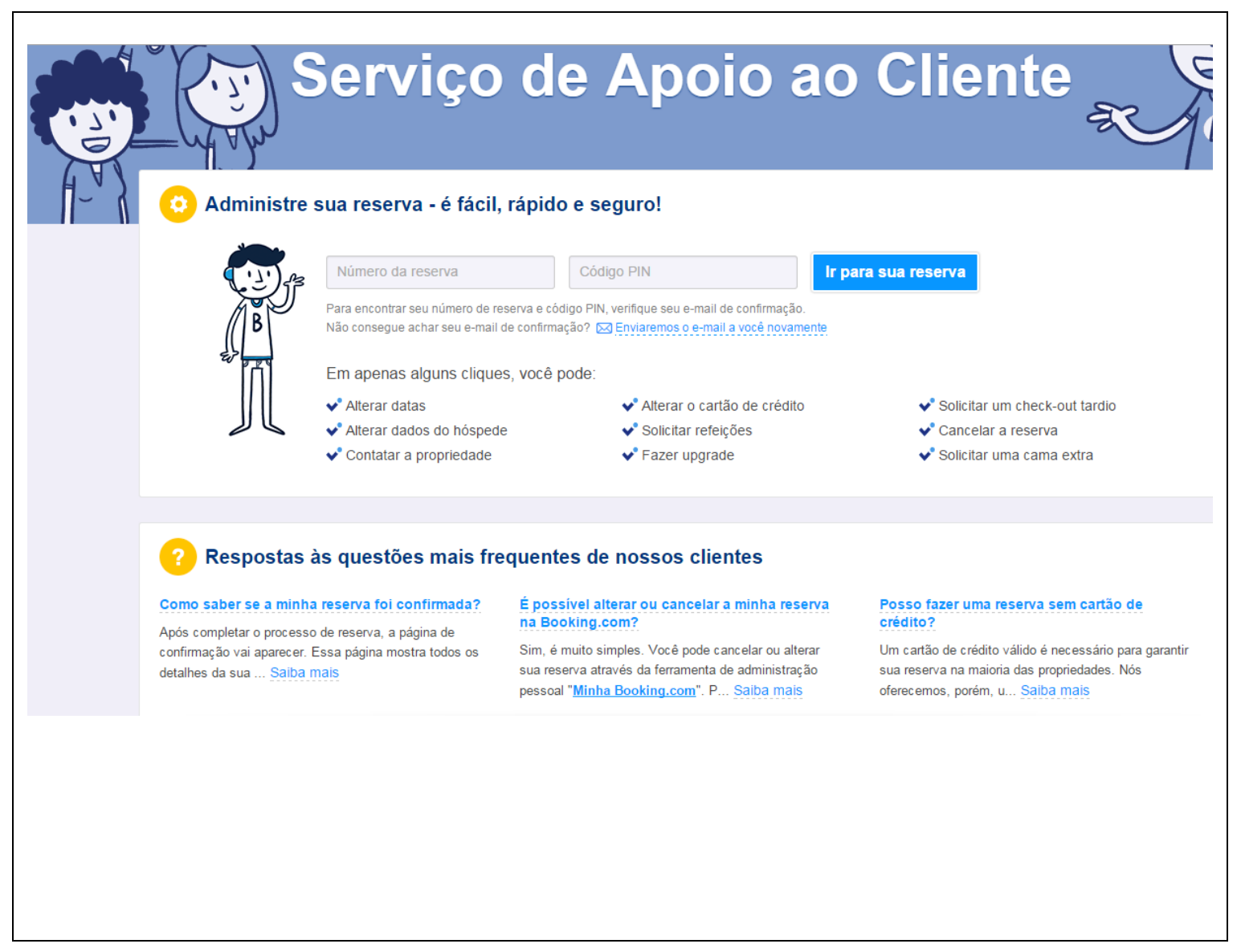

